\author{
Marta R. Trninić \\ Research Associate \\ University of Belgrade \\ Faculty of Mechanical Engineering
}

\section{Mathematical Modelling of Primary and Secondary Pyrolysis - State of the Art}

Pyrolysis process converts biomass into liquid, gaseous and solid fuels. Chemical kinetics play a key role in explaining the characteristics of pyrolysis reactions and developing mathematical models. Many studies have been undertaken to understand the kinetics of biomass pyrolysis; however, due to the heterogeneity of biomass and the complexity of the chemical and physical changes that occur during pyrolysis, it is difficult to develop a simple kinetic model that is applicable in every case. In this review, different methods to describe biomass primary and secondary pyrolysis with different types of kinetic mechanisms are discussed.

Keywords): pyrolsis, kinetics, mathematical modeling

\section{INTRODUCTION}

The development of thermochemical processes for biomass conversion and proper equipment design requires knowledge and good understanding of the chemical and physical mechanisms that are interacting in the thermal degradation process. The upsurge of interest in simulation and optimization of the reactors for thermochemical processes requires appropriate models that help to achieve a better understanding of the governing pyrolysis mechanisms, the determination of the most significant pyrolysis parameters and of their effect on the process and knowledge of the kinetics.

In spite of the great number (several hundred) of published papers, no consensus is presently reached in the literature. A great portion of publications have presented contradictory results, which induced a great deal of pessimism about the applicability of reaction kinetics for the evaluation of biomass pyrolysis [1]. The cause of the problem must be searched mainly in the application of oversimplified kinetic equations for processes composed of several chemical, physical, and physicochemical subprocesses [1]. Careless experimental work (e.g. kinetic parameters may vary according to the laboratory device, difficulties in measuring the actual biomass reaction temperature) and poor mathematical evaluation techniques have also contributed to the wrong performance of the reaction kinetics in this field [1].

The objectives of a mathematical pyrolysis model should include:

1. The development of a diagnostic tool in order to define the behaviour of the samples in a wide range of experimental conditions (particle size, heat of pyrolysis (reaction) and thermal properties of the feedstock and products) and to reveal similarities and differences between different biomass samples [2, 3]

2. The prediction of the behaviour outside the domain of the given set of observations in order to aid

Received: May 2020, Accepted: July 2020

Correspondence to: Dr Marta Trninić, University of

Belgrade, Faculty of Mechanical Engineering,

Kraljice Marije 16, 11120 Belgrade 35, Serbia

E-mail: mtrninic@mas.bg.ac.rs

doi:10.5937/fme2004733T

(C) Faculty of Mechanical Engineering, Belgrade. All rights reserved optimization of the pyrolysis process [2, 3]

3. The development and establishment of better reactor design techniques in order to specify reactor type and size [3].

Biomass pyrolysis involves numerous extremely complex reactions and end up with large number of intermediates and end products, devising an exact reaction mechanism and kinetic modelling for biomass pyrolysis is extremely difficult, hence, pyrolysis models are modelled on the basis of visible kinetics [4]. From a theoretical point of view, an endless variety and complexity of reactions forming a network can be assumed in biomass pyrolysis. Hence, even today it is difficult to develop a precise kinetic model taking into account all the parameters concerned.

This paper presents the state of the art in modelling chemical and physical processes of biomass pyrolysis. The review includes different mechanisms of kinetic modelling of the biomass primary and secondary pyrolysis process. Numerous models exist for the primary and secondary pyrolysis, each with their advantages and disadvantages. They range in complexity from simplest models to more mathematically complex models incorporating various factors which influence the kinetics of pyrolysis.

\section{KINETIC MODELING OF PRIMARILY AND SECONDARY PYROLYSIS}

\subsection{Semi - global kinetic models}

The semi-global models are used to describe primary and secondary solid degradation by means of experimentally measured rates of weight loss. Though one step models can predict the characteristic time of the pyrolysis process, for the formulation of engineering models with a view of reactor optimization and design, semi-global mechanisms appear to be more promising, because competitive chemical pathways are described, which allow product distribution to be predicted on dependence of reaction conditions [5]. The degradation of the three main biomass components is described through a kinetic mechanism, which deviates from the original Broido - Shafizadeh mechanism for the introduction of a linked tar and gas formation, Figure 1 [5]. Then the degradation rate of biomass is considered 
as the sum of the contribution of its main components, cellulose, hemicelluloses and lignin [5]. The extrapolation of the thermal behaviour of main biomass components to describe the kinetics of complex fuels is however, only a rough approximation because it has not been possible to establish exact correlations $[5,6]$. This is probably due to: the presence of inorganic matter in the biomass structure, which acts as a catalyst or an inhibitor for the degradation of cellulose, purity and physical properties of cellulose, which play an important role in the degradation process, noticeable differences in the hemicellulose and lignin, depending on the biomass type [5]. In addition, as it is impossible to isolate biomass components without affecting to varying extents their chemistry and structure, differences can be expected in the degradation mechanisms on dependence of the separation technique [5].

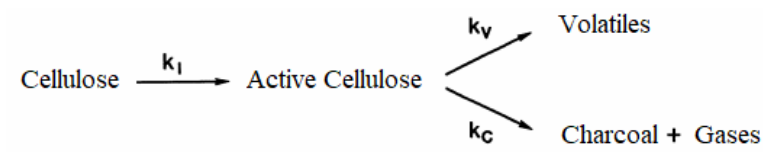

Figure 1. The Broido - Shafizadeh mechanism [5]

As well as for cellulose, wide interest in the primary pyrolysis of whole biomass has appeared in the literature (the pyrolysis of hemicelluloses and lignin). Várhegyi et al. [7, 8], performed several thermogravimetric experiments using: Avicel cellulose, 4-methylPglucurono-D-xylan (hemicellulose) and sugar cane bagasse, in the presence and absence of catalysts (inorganic salts). The three major DTG peaks were observed during the experiments resulted from decomposition of cellulose, hemicellulose, and lignin (main constituents of lignocellulosic materials). Thermogravimetric analysis showed a distinct DTG peak resulting from the decomposition of cellulose, than a lower DTG peak at lower temperature range resulting from hemicellulose pyrolysis, and an attenuated shoulder that can be attributed to lignin decomposition. Várhegyi et al. [8], showed that the mineral matter present in the biomass samples can highly increase the overlap of the partial peaks in DTG curves. Sometimes, the first peaks merge into one very broad peak [9]. Várhegyi et al. [7, $8,10]$, showed that pretreatments have influence on pyrolysis behaviour of lignocellulose materials. Thermal pretreatment destroys the hemicellulose component of the lignocellulose material but doesn't enhance the charcoal yield. Várhegyi, Grønli et al. [10], evidenced the ability of pretreatments to separate merged peaks, to displace reaction zones toward higher temperatures, decrease the charcoal yield and increase peak reaction rates $[10,11]$. The water washing, as one of pretreatments type, is preferred because it results in less hydrolysis and solubilisation of the holocellulose [9]. Also, the acid washes appeared to decrease the measured activation energy of cellulose pyrolysis [9].

As it is said, generally, from the thermogravimetric analysis (observing DTG curve) can be seen that temperature domains of moisture evolution and hemicellulose, cellulose and lignin decomposition more or less overlap each other. Considering this and also the results from experiments with biomass different pretreatments, it can be concluded that general biomass pyrolysis behaves as a superposition of the independent kinetics of the primary components (hemicellulose, cellulose, and lignin). The inability to predict the kinetic behaviour of biomass under different process conditions has encouraged researchers to develop complex multicomponent models. It is assumed that the true reaction system is too complex to be characterized in any fundamental way, so the reaction is described in terms of pseudo species, which are themselves complex materials or mixtures [12]. Absolute concentration is not important, as all species are characterized in terms of the fraction of their initial or final value [12]. The basic building block for all reactions is a pseudocomponent reaction [12]:

$$
\frac{d x}{d t}=\frac{\sum a_{i} d y_{i}}{d t}=k f(x)
$$

where $\mathrm{x}$ is the fraction of the initial material unreacted, $f(x)$ is a mathematical function of the unreacted initial material, $y_{i}$ is the $i$ th product of the reaction, and $\Sigma a_{i}=1$.

The simplest case is that of a pseudo-first-order reaction, for which $f(x)=x$. Other more complex functions will be discussed later. The $y_{i}$ values represent, for example, a partitioning into gaseous, liquid, and solid products. The pseudocomponents reactions can be presents as [12]:

$$
-\frac{d x}{d t}=\frac{\sum_{i} \sum_{j} \frac{a_{i j} d y_{i j}}{d t}}{d t}=\sum a_{j} k_{j} f\left(x_{j}\right)
$$

where $j$ represents the $j$ th component of $x$, $\sum a_{j} x_{j}=x, y_{i j}, y_{i j}$ is the $i$ th product of reaction component $j, \quad \sum_{i} \sum_{j} a_{i j}=1$, and $\sum_{i} a_{i j}=a_{j}$.

According to Di Blasi [13], there are two different approaches in pyrolysis of biomass modeling. The first approach assumes that the biomass is composed of three chemical components, (hemicellulose, cellulose and lignin), which react independently and, therefore, the thermal behaviour of biomass is also reflected by the individual behaviour of the biomass components, Figure 2. Each kind of biomass has unique specific proportions of the components present in it.

$$
\text { biomass component, } \mathrm{i} \stackrel{\mathrm{kj}_{\mathrm{j}}}{\longrightarrow} \text { volatile, } \mathrm{i}+\text { charcoal, } \mathrm{i}
$$

\section{Figure 2. One - step semi global model [13]}

Thurner and Mann [13, 14], investigated the kinetics of wood (oak sawdust) pyrolysis into gas, tar, and charcoal, to determine the reaction rate parameters, and to identify the composition of the pyrolysis products. It has been found that, in the range investigated, wood decomposition into gas, tar, and charcoal can be described by three parallel first-order reactions as suggested by Broido-Shafizadeh. They proposed the model which is an upgrade of the Broido-Shafizadeh model, Figure 3.

According to the model, wood is pyrolyzed into gas, tar, and charcoal according to three parallel reactions (reaction $\mathrm{k} 1, \mathrm{k} 2, \mathrm{k} 3$ ), called primary reactions, and the tar 
decomposes into gas and charcoal according to two parallel reactions (reaction $\mathrm{k} 4, \mathrm{k} 5$ ), called secondary reactions [14]. Each product in Figure 2 represents a sum of numerous components which are lumped together to simplify the analysis. The composition of each product, especially the distribution between the gas and the tar, depends, among other things, on the conditions under which the products are collected [14]. In principle, the reaction rate constants of these five reactions can be determined by measuring the amount of each product as a function of time. When the tar is removed from the reaction zone the secondary reactions are avoided and the reaction rate constants of the primary reactions can be determined directly from these measurements [14]. Table 1 presents evaluated kinetic parameters.

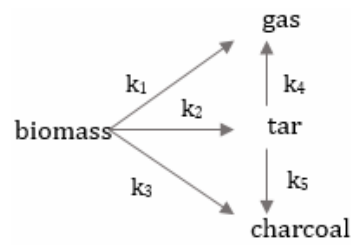

Figure 3. Biomass kinetic reaction scheme Thurner and Mann $[13,14]$

Table 1. Kinetic parameters used by Thurner and Mann [13, 14]

\begin{tabular}{|l|c|c|}
\hline $\begin{array}{l}\text { Reaction rate constant } \\
{\left[\mathrm{s}^{-1}\right]}\end{array}$ & $\begin{array}{c}\mathrm{A} \\
\left(\mathrm{s}^{-1}\right)\end{array}$ & $\begin{array}{c}\mathrm{E} \\
(\mathrm{kJ} / \mathrm{mol})\end{array}$ \\
\hline $\mathrm{k}_{1}$ & $1.43 \cdot 10^{4}$ & 88.6 \\
\hline $\mathrm{k}_{2}$ & $4.12 \cdot 10^{6}$ & 112.7 \\
\hline $\mathrm{k}_{3}$ & $7.37 \cdot 10^{5}$ & 106.5 \\
\hline
\end{tabular}

Koufopanos et al [15] attempted to correlate the pyrolysis rate of the biomass with its composition. Koufopanos et al [15], proposed kinetic model based on experimental results preformed experiment of pyrolysis of fine particles of lignocellulosic materials (below 1 $\mathrm{mm}$ ) in size. In this case, the possible effects of heat and mass transfer phenomena are drastically decreased and the process is controlled by kinetics. The good fit of the kinetic model to experimental data obtained under different heating conditions and over a wide temperature range suggests that the pyrolysis rate of fine particles can be interpreted in terms of pyrolysis temperature and solid residence time [15]. This model is presented in Figure 4.

This model uses an intermediate step (initial reaction $\mathrm{k} 1)$ to get an activated sample. This initial reaction (k1) describes the overall results of the reactions prevailing at lower pyrolysis temperatures (below $473 \mathrm{~K}$ ) [4]. This first step is considered to be of zero-order and is not associated with any weight loss. The intermediate formed further decomposes through two competitive reactions, to charcoal (reaction $\mathrm{k} 3$ ) and to gaseous /volatile products (reaction k2) [4]. This model is relatively simple and can predict the final charcoal yield in different heating conditions.

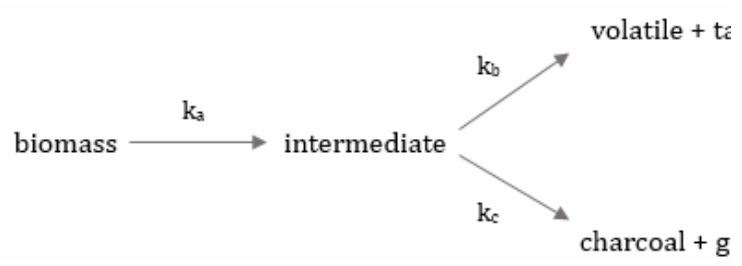

Figure 4. Reaction scheme of Biomass Pyrolysis suggested by Koufopanos [15], a, b, c - share of biomass components

Kinetic parametars used by Koufopanos are presented in Table 2. The proposed kinetic model for the pyrolysis of lignocellulosic materials is relatively simple and predicts with sufficient accuracy both the reaction rate (expressed in terms of weight-loss) and the charcoal yield, also model can be used for the interpretation of experimental data and for the design of biomass thermochemical conversion apparatus, [15]. Another set of conclusions emerging from this work relates to the relationship between the biomass pyrolysis rate and the biomass composition; it was found to be possible to analyse biomass pyrolysis by considering the biomass as the sum of its main components: cellulose, lignin and hemicellulose [15].

One of the first researches who introduced this idea of pseudocomponents was Orfao et al [16] proposed a method to determine biomass composition based on experimental results. The behaviour of biomass components (cellulose, hemicelluloses and lignin) was experimentaly studied thermogravimetrically with linear temperature programming, under nitrogen and air [16]. Three commercial products were taken as representative of biomass components: cellulose (Avicel PH101, FMC Corporation), xylan (code X0627, Sigma) and lignin from pine wood (Westvaco Co.), sawdust from pine wood (Pinus pinaster), eucalyptus (Eucalyptus globulus) and pine bark [16]. Small particle sizes were chosen in order to avoid mass and heat transfer resistances.

The pyrolysis of biomass was successfully modelled by a kinetic scheme consisting of three independent frst order reactions of three pseudo components (hemicellulose, cellulose and lignin). In the model, the kinetic parameters of the second pseudo component, which were previously determined, were fixed. They noted that thermal decomposition of xylan and lignin could not be modelled with acceptable errors by means of simple reactions (minimum deviations were $15 \%$ and $10 \%$, respectively) [16]. Orfao et al. [16] defined three pseudocomponents for describing the primary thermal decomposition of pine and eucalyptus woods and pine bark.

Table 2. Kinetic parameters, Koufopanos et al. [8]

\begin{tabular}{|l|c|c|c|c|c|c|c|c|c|}
\hline \multirow{2}{*}{$\begin{array}{l}\text { Biomass } \\
\text { component }\end{array}$} & \multicolumn{3}{|c|}{ First reaction } & \multicolumn{3}{c|}{ Second reaction } & \multicolumn{3}{c|}{ Third reaction } \\
\cline { 2 - 10 } & $\mathrm{n}$ & $\begin{array}{c}\mathrm{A} \\
\left(\mathrm{s}^{-1}\right)\end{array}$ & $\begin{array}{c}\mathrm{E} \\
(\mathrm{kJ} / \mathrm{mol})\end{array}$ & $\mathrm{n}$ & $\begin{array}{c}\mathrm{A} \\
\left(\mathrm{s}^{-1}\right)\end{array}$ & $\begin{array}{c}\mathrm{E} \\
(\mathrm{kJ} / \mathrm{mol})\end{array}$ & $\mathrm{n}$ & $\begin{array}{c}\text { A } \\
\left(\mathrm{s}^{-1}\right)\end{array}$ & $\begin{array}{c}\mathrm{E} \\
(\mathrm{kJ} / \mathrm{mol})\end{array}$ \\
\hline cellulose & 0 & $2.2 \cdot 10^{14}$ & 167.5 & 1.5 & $94 \cdot 10^{15}$ & 216.5 & 1.5 & $3.110^{13}$ & 196 \\
\hline hemicellulose & 0 & $3.3 \cdot 10^{6}$ & 72.4 & 1.5 & $1.1 \cdot 10^{14}$ & 174.1 & 1.5 & $2.510^{13}$ & 172 \\
\hline lignin & 0 & $3.3 \cdot 10^{12}$ & 147.7 & 1.5 & $8.6 \cdot 10^{8}$ & 137.1 & 1.5 & $4.410^{7}$ & 122 \\
\hline
\end{tabular}


The pyrolysis of lignocellulosic materials was successfully modelled by a kinetic scheme consisting of three independent first-order reactions of three pseudocomponents. The first and the second pseudocomponents correspond to the fractions of hemicellulose and cellulose which are reactive at low temperatures and the third includes lignin and the remaining fractions of the carbohydrates [16].

Reasonable agreement was obtained between the activation energies calculated for the other pseudo components and reported values. Later, Manyà et al. $[16,17]$ the thermal decompositions of sugarcane bagasse and waste-wood samples studied using thermogravimetric analysis. First, an irreversible first order reaction model was assumed for each pseudocomponent, but results showed that the model simulated curves do not fit well to the experimental data. Manyà et al. [17] with kinetic study presented that pyrolysis of lignin is better described by a third-order reaction rate law. The reformulation of the lignin kinetic model, and its subsequent implementation in the summative model (for the third pseudocomponent), has allowed one to reach a good agreement between simulated and experimental data [11]. Later, Mészáros et al. and Diaz [9, 17] showed satisfactory results when several partial reactions for corresponding pseudocomponents were assumed in the decomposition of a wide variety of biomass materials.

The goal of the kinetic evaluation is to obtain better, more informative results from the experiments. In the attempt to better identify the zones associated with the devolatilization of the biomass components and their overlapped kinetics, different $\mathrm{T}(\mathrm{t})$ heating programs have been employed [9]. Mészáros et al. [17] increased the information content of the experiments by involving successive non-isothermal steps into their study. A wider range of the experimental conditions reveals more of the chemical inhomogeneities of the biomass components [17]. Linear and stepwise heating programs were employed to increase the amount of information in the series of experiments [18]. Employing non isothermal experiments, not only identification of pseudocomponents or zones were possible to made (hemicellulose, cellulose and lignin), but also, the contribution of extractives or more than one reaction stage in the decomposition of components, especially hemicellulose and lignin, could be also taken into pyrolysis kinetic analysis account.

Experimental measurements of the pyrolytic behaviour of biomass have been the focus of extraordinary interest in the research community, but practical problems associated with these measurements have often been overlooked. The most important errors are connected to problems of temperature measurements and to the self-cooling/self-heating of samples due to heat demand by the chemical reaction [9]. A consequence of these limitations is that the single step activation energy measured at high heating rates is almost always lower than its true value [9]. Another consequence is that weight loss is reported at temperatures much higher than it actually occurs [9]. All mentioned, are possible reasons for gross disagreements in the literature concerning the kinetics of pyrolysis.
For example, Antal and Várhegyi [19] concluded that the pyrolysis of a small sample of pure cellulose is characterized by an endothermic reaction governed by a first-order rate law with a high activation energy (ca. $238 \mathrm{~kJ} / \mathrm{mol}$ ). Almost immediately after the paper was published, these conclusions were contradicted by the findings of Milosavljevic and Suuberg [20], claim that the cellulose thermal degradation can be well described by a two-stage mechanism: the first at a low-temperature range with high activation energy $(218 \mathrm{~kJ} / \mathrm{mol})$ and the second at a high-temperature range with reduced activation energy (140-155 kJ/mol). Antal et al. [21] measured the rates of pyrolysis of the same cellulose employed by Milosavljevic and Suuberg [20], in Antal's laboratory equipment. Also, the kinetics of other cellulose samples was studied to learn if different pure celluloses evidence markedly different pyrolysis behaviour. The mass used for samples by Milosavljevic and Suuberg (30 mg) causes diffusion effects and, subsequently, an increase in the residence time for the vapour fraction, which promotes secondary reactions [21]. Also, the thermal lag (between the thermocouple lecture and the real temperature of the sample) accentuates the compensation effect [21]. This phenomenon causes an erratic estimation for the kinetic parameters [21]. If heat transfer effects cannot be neglected, then the kinetic model may not be adequate for describing the behaviour of the process involved, and must be combined with heat transfer equations [9]. It is difficult to combine a realistic modeling of the heat transfer phenomena with complex chemical kinetic models [9]. An alternative way is the empirical assessment of systematic errors [9]. To specify the serious trouble that supposes the experimental error, Grønli et al. [22] coordinated the realization of a round-robin kinetic study for the cellulose pyrolysis (Avicel PH-105) in eight European laboratories.

Results confirmed the theories of Antal et al. [21] but also alerted the scientific community about the convenience of carrying out this experiment (under standard conditions) in order to be able to quantify their own experimental errors $[11,22]$.

The second approach involves biomass as a single homogeneous sample whose thermal decomposition takes place according to semi - global model [13]. A model is based on Shafizadeh's model.

Compared with primary reactions, secondary reactions are less investigated and evaluations of the kinetic constants are essentially available only for the cracking process. The least understood aspect of pyrolysis is the interaction of the nascent, hot pyrolysis vapours with the decomposing solid, which vapours must traverse during their escape to the environment [9]. That process has been identified as secondary decomposition. At high temperatures and given sufficiently long residence times, secondary reactions of primary tar vapours also become active [23-26]. These alter both the yields and composition of the biomass pyrolysis products. They may occur in the pores of the particles, while undergoing primary degradation, homogeneously in the vapour phase and heterogeneously over the charcoal surfaces and the extra-particle surfaces [26]. Secondary reactions of tar vapours include 
processes such as cracking, partial oxidation, repolymerization and condensation. It is worth to mention that extensive research on biomass gasification confirm the catalytic effects exerted by different materials on the cracking of tarry components.

However, despite the quantitative understanding about the chemical composition of this class of products, the most cited mechanism simply consists of two competing reactions [26], as reported in Figure 5.

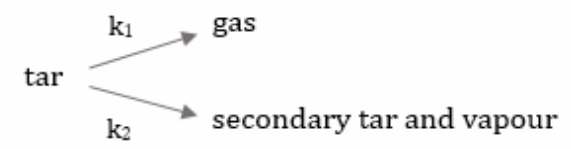

biomass $=\mathrm{a}$ hemicellulose $+\mathrm{b}$ cellulose $+\mathrm{c}$ lignir

Figure 5. A global mechanism for the secondary reactions of vapour-phase tarry species as proposed by Antal [24, 25]

The reactive volatile matter is assumed to be consumed by two competitive reactions leading to the formation of permanent gases and a refractory condensable material. The competition between the chemical paths of gas and refractory tar formation has important implications from the point of view of process development [26].

The kinetics of secondary tar reactions is also of paramount importance in biomass gasification. The amount of tar produced and its composition depend on the type of gasifier and the process conditions. In principle, producer gas with a low tar content can be obtained if a high-temperature zone can be created where the volatile products of pyrolysis are forced to reside sufficiently long to undergo secondary gasification [26]. However, the discovery of a refractory tar product of secondary reactions has motivated extensive research activities on catalytic pyrolysis for the vapour phase products which, as anticipated, have been reviewed [26].

Chan et al [27, 28], have also included dehydration reactions along with the tar cracking to the competing reaction model. Model of independent parallel reactions was successfully used to describe the thermal decomposition of biomass. Model includes three independent parallel reaction of gas, charcoal and tar formation, and one reaction of tar decomposition to gas and secondary charcoal, Figure 6. Kinetic parameters are evaluated by use of this kinetic model are presented in Table 3.

The interaction involves an exothermic reaction which leads to the formation of charcoal. The role of such reactions is minimized by conditions which facilitate rapid mass transfer Antal and Grønli [29]. The majority of studies dealing with secondary reactions have been based on sensitivity analysis but a few number of practical models have included it. Srivastava et al. [30] extended the Koufopanos mechanism. Proposed kinetic model based on experimental results of pyrolysis of different biomass in isothermal and nonisothermal conditions. The operative temperature ranges from 573 to $973 \mathrm{~K}$ for isothermal conditions and, for non-isothermal conditions, the heating rate ranges from 5 to $80 \mathrm{~K} / \mathrm{min}$ [30]. It was found that the model developed was in excellent agreement with the experimental data. The pyrolysis model is presented in Figure 7.

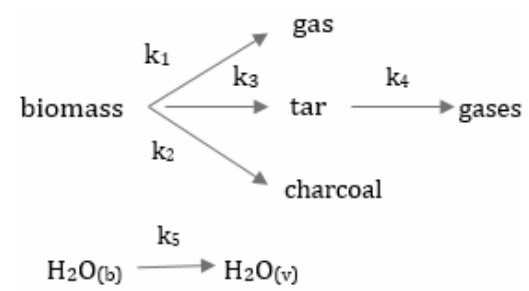

Figure 6. Scheme of Biomass Pyrolysis model duggested by Chan et al $[27,28]$

Table 3. Kinetic parameters used by Chan et al [27, 28]

\begin{tabular}{|l|c|c|c|}
\hline Reaction & $\begin{array}{c}\mathrm{A} \\
\left(\mathrm{s}^{-1}\right)\end{array}$ & $\begin{array}{c}\mathrm{E} \\
(\mathrm{kJ} / \mathrm{mol})\end{array}$ & $\begin{array}{c}\Delta \mathrm{h} \\
(\mathrm{kJ} / \mathrm{kg})\end{array}$ \\
\hline 1 & $1.3 \cdot 10^{8}$ & 140.3 & 209.3 \\
\hline 2 & $2.0 \cdot 10^{8}$ & 133.1 & 209.3 \\
\hline 3 & $1.1 \cdot 10^{7}$ & 121.4 & 209.3 \\
\hline 4 & $1.48 \cdot 10^{6}$ & 114.3 & -2009.3 \\
\hline 5 & $5.13 \cdot 10^{6}$ & 88.0 & 2257 \\
\hline
\end{tabular}

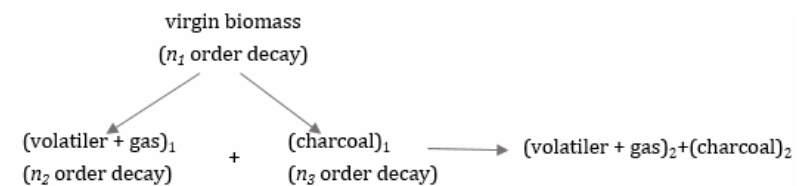

\section{Figure 7. Model of Srivastava et al. [30]}

This model indicates that the biomass decomposes to volatiles, gases and charcoal. The volatiles and gases may further react with charcoal to produce different types of volatiles, gases, and charcoal where the compositions are different. Therefore, the primary pyrolysis products participate in secondary interactions (reaction k3), resulting in modified final product distribution. It suggests that the gases and volatiles can react with the charcoal to produce different types of volatiles, gases and charcoals. When the volatiles and gases are transported by a gas flow, the secondary reaction will be affluent.

Concerning kinetic modelling, Di Blasi [31] presented an approach describing the kinetics according to a competitive reaction scheme (Figure 8). In this model biomass decomposes via three competing reactions into gas, charcoal and tar. The secondary reaction takes place in the gas/vapour-phase within the pores of the charcoal. Consecutively the tar is converted by two secondary reactions into secondary gasses and charcoal. The rate of the reaction is proportional with the concentration of the tar vapours. Kinetics parameters are presented in Table 4.

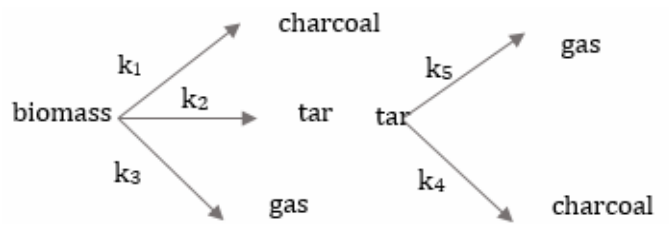

Figure 8. Reaction scheme of Biomass Pyrolysis suggested by Di Blasi [31]

The Miller - Bellan model shown in Figure 9.

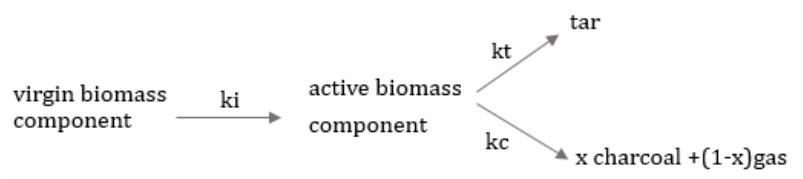

Figure 9. Miller-Bellan model [32] 
Table 4. Kinetic parameters used by Di Blasi [31]

\begin{tabular}{|l|c|c|c|}
\hline Reaction & $\begin{array}{c}\mathrm{A} \\
\left(\mathrm{s}^{-1}\right)\end{array}$ & $\begin{array}{c}\mathrm{E} \\
(\mathrm{kJ} / \mathrm{mol})\end{array}$ & $\begin{array}{c}\Delta \mathrm{h} \\
(\mathrm{kJ} / \mathrm{kg})\end{array}$ \\
\hline 1 & $5.16 \cdot 10^{6}$ & 100 & 418 \\
\hline 2 & $1.49 \cdot 10^{10}$ & 121 & 418 \\
\hline 3 & $2.66 \cdot 10^{10}$ & 112 & 418 \\
\hline 4 & $4.28 \cdot 10^{6}$ & 108 & -42 \\
\hline 5 & $1.00 \cdot 10^{6}$ & 108 & -42 \\
\hline
\end{tabular}

The chemical pyrolysis reactions are modelled using the modified Broido - Shafizadeh scheme. This model has the advantage that it is one of the most complete models available. The scheme provided by Miller and Bellan [32] is able to deal with varying heating rates through the different reaction paths, and the model can deal with variations in fuel composition since it uses three fuel species instead of one model specie for biomass. In this two-step scheme the virgin fuel is first converted into an activated variant, which on its turn is converted into pyrolysis products. The scheme is applied for all three biomass model components with different kinetic constants. Kinetics parameters are listen in Table 5.

Compared with primary reactions, secondary reactions are less investigated. Most of the kinetic models are based on the primary pyrolysis analysis, only few models includes secondary reactions which take place outside of the biomass samples. Gvero [13], Rath and Staudinger [33], emphasize that the main product of the primary pyrolysis is tar, complex mixture of different organic compounds. Secondary reactions of tar vapours are classified as homogeneous and heterogeneous and include processes such as cracking, partial oxidation, re-polymerization and condensation. The complex chemical composition of tarry products would require a huge number of chemical reactions to describe the details of the transformations [26]. The existence of the second reaction is inferred from the gas yield data, which display an asymptotic behaviour (after residence times of about $5 \mathrm{~s}$ ) that is strongly dependent on temperature; higher temperatures result in dramatic increases in the asymptotic yields of all the light permanent gases produced [26]. The temperaturedependent asymptotes require the existence of the second reaction in order to explain the disappearance of carbon atoms in the gas phase when the gas phase temperature is reduced [26].

Borson et al [34], the homogeneous vapour phase cracking of newly formed wood pyrolysis tar studied at low molar concentrations as a function of temperature (773-1073 K), at residence times of 0.9-2.2 s [34]. Quantitative yields and kinetics were obtained for tar cracking and resulting products formation. The tar yield at $1 \mathrm{~K} / \mathrm{s}$ and temperature of $600 \mathrm{oC}$ is $30 \mathrm{wt} \%$, while at $800 \mathrm{oC}$ is $80 \mathrm{wt} \%$. The major tar conversion product was carbon monoxide, which accounted for over two-thirds of the tar lost (even up to $50-70 \mathrm{wt} \%$ ) at high severities [34]. Corresponding ethylene and methane yields were each about $10 \%$ of the converted tar; charcoal formation was negligible and weight-average tar molecular weight declined with increasing tar conversion [34].

Morf [35, 36], the change of mass and composition of biomass tar due to homogeneous secondary reactions experimentally studied by means of a lab reactor system that allows the spatially separated production and conversion of biomass tar. Homogeneous secondary tar reactions without the external supply of oxidising agents were studied in a tubular flow reactor operated at temperatures from 500 to $1000{ }^{\circ} \mathrm{C}$ and with space times below $0.2 \mathrm{~s}$ [36]. It is shown that, under the reaction conditions chosen for the experiments, homogeneous secondary tar reactions become important at temperatures higher than $650{ }^{\circ} \mathrm{C}$, which is indicated by the increasing concentrations of the gases $\mathrm{CO}, \mathrm{CH}_{4}$, and $\mathrm{H}_{2}$ in the pyrolysis gas [36]. The gravimetric tar yield decreases with increasing reactor temperatures during homogeneous tar conversion. The highest conversion reached in the experiments was $88 \%$ at a reference temperature of $990^{\circ} \mathrm{C}$ and isothermal space time of 0.12 s [36]. Hydrogen is a good indicator for reactions that convert the primary tar into aromatics, especially PAH. Soot appears to be a major product from homogeneous secondary tar reactions [36].

Innovative approach to secondary reaction kinetic modelling is presented by Rath и Staudinger [33]. Тhe model is presented in Figure 10. Applying a coupling of a TGA and a tubular reactor, the investigation of the particular cracking characteristics of tar from pyrolysis of spruce wood as a function of the temperature was done.

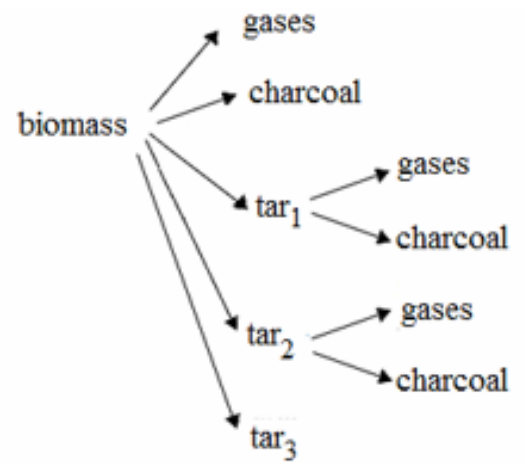

Figure 10. Reaction scheme of Biomass Pyrolysis suggested by Rath $и$ Staudinger [33]

The experimental results showed that the extent of tar cracking is not only dependent on the conditions in the cracking reactor (temperature and residence time) but also on the temperature at which the tar was formed.

During fast biomass pyrolysis, relatively high amount of tar is produced. This tar,which may reach up to $70 \%$, is an extremely complex mixture. The tar could be classified, as a result of biomass pyrolysis, into three major classes: primary, secondary and tertiary tars.

Primary tar is formed due to the presence of oxygen compounds in a temperature range of 400-700 oC. Secondary tar is formed in a temperature range of 700$850 \mathrm{oC}$, and it includes phenolics and olefins. Tertiary tar products appear in the temperature regime of 850$1000 \mathrm{oC}$ and are characterized by aromatics.

Sometimes, these three main classes are divided into sub-classes as well. During thermal biomass pyrolysis, the tar classes are formed and cracked hereafter. However, some of such tar classes and in particular their compounds are not fully cracked at pyrolysis process where some of which are left and they are so called non-reactive tars. Their values are mainly attributed to the structure of biomass and type of pyrolysis process (slow or fast). 
Table 5. Kinetic parameters for the pyrolysis reactions [32]

\begin{tabular}{|l|c|c|c|c|c|c|}
\hline & \multicolumn{2}{|c|}{ Cellulose } & \multicolumn{2}{c|}{ Hemicellulose } & \multicolumn{2}{c|}{ Lignin } \\
\hline & $\begin{array}{c}\mathrm{A} \\
\left(\mathrm{s}^{-1}\right)\end{array}$ & $\begin{array}{c}\mathrm{E} \\
(\mathrm{kJ} / \mathrm{mol})\end{array}$ & $\begin{array}{c}\mathrm{A} \\
\left(\mathrm{s}^{-1}\right)\end{array}$ & $\begin{array}{c}\mathrm{E} \\
(\mathrm{kJ} / \mathrm{mol})\end{array}$ & $\begin{array}{c}\mathrm{A} \\
\left(\mathrm{s}^{-1}\right)\end{array}$ & $\begin{array}{c}\mathrm{E} \\
(\mathrm{kJ} / \mathrm{mol})\end{array}$ \\
\hline $\mathrm{ki}$ & $2.80 \mathrm{E} 19$ & 242.4 & $2.10 \mathrm{E} 16$ & 186.7 & $9.60 \mathrm{E} 8$ & 107.6 \\
\hline $\mathrm{kt}$ & $3.28 \mathrm{E} 14$ & 196.5 & $8.75 \mathrm{E} 15$ & 202.4 & $1.50 \mathrm{E} 9$ & 143.8 \\
\hline $\mathrm{kc}$ & $1.30 \mathrm{E} 10$ & 150.5 & $2.60 \mathrm{E} 11$ & 145.7 & $7.70 \mathrm{E} 6$ & 111.4 \\
\hline
\end{tabular}

Primary tars 1 and 2 cracking according a simple first order over all kinetic model (equation 3). Primary tar 3 does not crack (equation 4).

$$
\begin{aligned}
& n\left[\frac{\frac{d \alpha}{d t}}{(1-\alpha)}\right]=\ln A-\frac{E}{R T} \\
& -r_{\text {ter }, i}=A_{i} e^{-\frac{E i}{R T}} C_{\text {tar }, i}
\end{aligned}
$$

where $r_{t e r, \mathrm{i}}\left(\mathrm{mg} / \mathrm{gm}^{3} \mathrm{~s}^{1}\right)$ is tar rate, and $C_{t e r, i}\left(\mathrm{mg} / \mathrm{gm}^{3}\right)$ tar concentration.

It was assumed that there exists a linear correlation between the rate of tar cracking and the rate of carbon monoxide formation from tar cracking. This assumption was extended to all gaseous components. Therefore the formation of the individual product gases $j$ from tar cracking can be described according to equation 5 using the rates of tar cracking (cracking of tars $i=1$ and $i=2$, tar 3 does not crack) and constant yield coefficients $Y_{j, i}$.

$$
r_{i}=\sum_{i=1}^{2}\left(-r_{t a r, i}\right) Y_{i j}
$$

where $r_{j}\left(\mathrm{mg} / \mathrm{gm}^{3} \mathrm{~s}\right)$ is the rate of reaction and $\mathrm{Y}_{j, i}(\mathrm{~g} / \mathrm{g})$ is the yield coefficient. Table 6 shows the kinetic parameters calculated for the vapour phase cracking of the tars from pyrolysis of birch wood determined within this work.

Table 6. Kinetic Parametars of three parallel reaction of tar decomposition [13, 33]

\begin{tabular}{|l|c|c|}
\hline & $\mathrm{E}(\mathrm{kJ} / \mathrm{mol})$ & $\mathrm{A}\left(\mathrm{s}^{-1}\right)$ \\
\hline primary tar & 66.3 & $3.076 \cdot 10^{3}$ \\
\hline secondary tar & 109 & $1.13 \cdot 10^{6}$ \\
\hline tertiary tar & \multicolumn{2}{|c|}{ no cracking } \\
\hline
\end{tabular}

The simplest models were based on a single decomposition reaction, and they do not allow to predict the influence of pyrolysis conditions on the amount of products [26]. Other models assume some parallel reactions to predict the production kinetics of gas tar and charcoal. More complex reaction schemes were also adopted, involving a further decomposition of tar in the gas phase or an intermediate product deriving from primary decomposition of biomass, giving rise to gas, tar charcoal. Most of these models were developed on the basis of experimental results obtained by pyrolysis of few mg of biomass in powder, often with a very high increase of temperature.

Based on the literature review, there are two approaches in biomass pyrolysis modelling. The first approach takes into account that the biomass is composed of three pseudocomponents (hemicellulose, cellulose and lignin), which thermally decompose independently of each other. Thermal decomposition of pseudocomponents are explain by single range reactions. This approach results in large number of experimental data ( $k i, E i, A i)$. The second approach, comprises multicomponential devolatalisation reactions, and include the primary and secondary reactions.

\subsection{A distributed activation energy model for the pyrolysis of lignocellulosic biomass - DEAM}

The complex composition of biomass materials, the conventional linearization techniques of the nonisothermal kinetics are not suitable for the evaluation of the TGA experiments. As it is mentioned several times, biomass contain a wide variety of pyrolyzing species. Even the same chemical species may have a different reactivity if its pyrolysis is influenced by other species in its vicinity [18]. As biomass is heated, its components (hemicellulose, cellulose and lignin) become chemically unstable and thermally degrade or vaporise. The thermal degradation of each component occurs at different temperature by different pathways. The decomposition of the hemicellulose is carries out at temperatures $200-260^{\circ} \mathrm{C}$, cellulose $240-350^{\circ} \mathrm{C}$ and lignin $280-500^{\circ} \mathrm{C},[37,38]$. The basic knowledge of the role and behaviour of the three principal components of biomass (cellulose, hemicelluloses and lignin) during pyrolysis is important for understanding and controlling this process. The assumption of a distribution in the reactivity of the decomposing species frequently helps the kinetic evaluation of the pyrolysis of complex organic samples [18, 39]. The chemical complexity of both the biomass and the related pyrolysis products motivate the introduction of kinetic models based on kinetic laws different from those presented above. The distributed activation energy model (DAEM) is the best way to represent mathematically the physical and chemical inhomogeneity of a substance $[18,39,40]$.

The concept of a distributed activation energy as originally proposed by Vand [41] was adapted to the problem of coal devolatilization by Pitt [42]. Pitt [42], first treated the coal as a mixture of a large number of species decomposing by parallel first order reactions with different activation energies. The pyrolysis behaviour of coal is described as a complex of firstorder reactions, each with its own rate constants. Further work carried out by Anthony and Howard [43], and Braun and Burnham [44], modified the model developed by Pitt and extended its use to coal, biomass and even blends of the two. 
Distributed activation energy models have been used for biomass pyrolysis kinetics since 1985,when Avni et al. [39] applied a DAEM for the formation of volatiles from lignin. Later this type of research was extended to a wider range of lignocellulose materials. Saidi et al. [45], employed DAEM-based kinetic models in establishing an actual combustion model of a burning cigarette. A three-dimensional model for a puffing cigarette was constructed using the principles of the conservation of mass and momentum. To do this, an average temperature-time history of a burning cigarette was derived using existing experimental data for the temperature distribution in a cigarette [45].

Várhegyi et al. [46] studied decomposition of two tobacco blends by thermogravimetry-mass spectrometry (TGA-MS) at slow heating programs under welldefined conditions. The kinetic evaluation was based on a distributed activation energy model (DAEM). The complexity of the studied materials required the use of more than one DAEM reaction [46].

The resulting models describe well the experimental data and are suitable for predicting experiments at higher heating rates. Várhegyi et al. [46, 47] , Trninic [48], Trninic et al. [18], based DAEM kinetic studies on the simultaneous evaluation of experiments with linear and stepwise temperature programs. The model parameters obtained in this way allowed accurate prediction outside of the domain of the experimental conditions of the given kinetic evaluations [18]. The determination of the unknown model parameters and the verification of the model were based on the least squares evaluation of series of experiments [47]. This approach led to favourable results and allowed predictions outside the experimental conditions of the experiments used in the parameter determination [40, 47].

The distributed reactivity is usually approximated by a Gaussian distribution of the activation energy due to the favourable experience with this type of modelling on similarly complex materials [18]. According to this model, the sample is regarded as a sum of $\mathrm{M}$ pseudocomponents, where $\mathrm{M}$ is usually between 2 and 4 [18]. Here pseudocomponent is the totality of those decomposing species which can be described by the same reaction kinetic parameters in the given model [18]. The reactivity differences are described by different activation energy values. At a molecular level, each species in pseudocomponent $\mathrm{j}$ is assumed to undergo a first-order decay [18].

\section{Derivation of DAEM}

The key concept of the DAEM is to compress the manifold diversity (appearing in composition, structure, reaction complexity) into a proper set of kinetic parameters [49]. The biomass sample is assumed to contain $1,2, \ldots, j, \ldots M$ distinguishable constituents (pseudocomponent). In the pyrolysis. Regard to this, denote the unreacted constituent of biomass represented by the $j$ th kinetic equation as $\alpha j$. The normalized biomass mass $m$ is the linear combinations of $\alpha j(t)$ :

$$
m(t)=1-\sum_{j=1}^{M} \mathrm{c}_{\mathrm{j}} \alpha_{j}(t)
$$

where a weight factor $c_{j}$ is equal to the amount of volatiles formed from a unit mass of pseudocomponent $j$. $M$ denotes the number of partial reactions contributing to the given measured quantities. If $M=1$, there is only one $c$, which is a proportionality factor between the reaction rate and the observed quantity. When $M>1$ (i.e., when the observed curve is composed of overlapping partial curves) $c j$ represents the contribution of the $j$ th partial reaction to the measured quantity [40].

The following boundary conditions apply to functions $\alpha_{j}(t)$ [40]:

$$
\alpha_{j}(t=0)=1 \text { (mass of pseudocomponent } j \text { at the }
$$

beginning of the process)

$\alpha_{j}(\infty)=0$ (mass of pseudocomponent $j$ at the end of the process)

The derivative of the normalized sample mass $m$ :

$$
-\frac{d m}{d t}=\frac{\sum_{j=1}^{M} \mathrm{c}_{\mathrm{j}} d \alpha_{j}}{d t}
$$

The overall reaction rate is a linear combination of these partial reactions $d \alpha_{j} / d t,[50,51]$ :

$$
-\frac{d m^{\text {calc }}}{d t}=\frac{\sum_{j=1}^{M} \mathrm{c}_{\mathrm{j}} d \alpha_{j}}{d t}
$$

Each partial reaction is approximated by an Arrhenius equation. The corresponding rate constant $k$ and mean lifetime $\tau$ are supposed to depend on the temperature by an Arrhenius formula:

$$
\frac{d \alpha_{j}}{d t}=\mathrm{A}_{\mathrm{j}} \exp \left(-\frac{E_{j}}{R T}\right)\left(1-\alpha_{j}\right)^{n j}
$$

where $A_{j}$ is the preexponential factor of the jth pseudocomponent and $E_{j}$ is the activation energy of the jth pseudocomponent.

If $\alpha j(t, E)$ is the solution of the corresponding firstorder $(n=1)$, kinetic equation. at a given $E$ and $T(t)$ with conditions $\alpha_{\mathrm{j}}(0, E)=1$ and $\alpha_{j}(\infty, \mathrm{E})=0$, became [40]:

$$
-\frac{d \alpha_{j}(t, E)}{d t}=A_{j} \exp \left[-\frac{E}{R T(t)}\right]\left[1-\alpha_{j}(t, E)\right]
$$

where $T(t)$ is the temperature of the reacting particle.

The density function of the species differing by $\mathrm{E}$ within a given pseudocomponent is denoted by $\mathrm{Dj}$. The overall reacted fraction of the $\mathrm{jth}$ pseudocomponent, $\alpha \mathrm{j}(\mathrm{t})$, is obtained by integration [40]:

$$
\alpha_{j}(t)=\int_{0}^{\infty} D_{j}\left(E_{a}\right) X_{j}(t, E) d E
$$

$\operatorname{Dj}(\mathrm{E})$ is approximated by a Gaussian distribution with mean Eo,j and width-parameter (variation) $\sigma \mathrm{j},[18$, 40]: 


$$
D_{j}(E)=(2 \pi)^{\frac{1}{2}} \sigma_{j}^{-1} \exp \left[-\frac{\left(E-E_{0 j}\right)^{2}}{2 \sigma_{j}^{2}}\right]
$$

where $d \propto j / d t$ curves can be written as [40]:

$$
\frac{d \alpha_{j}(t)}{d t}=\frac{\int_{0}^{\infty} D_{j}(E) d \alpha_{j}(t, E)}{d t d E}
$$

Due to the fact that there is an inner $d T$ integral and outer $d E$ integral in the DAEM, it is very difficult to obtain the exact analytical solution of the DAEM. Since it is difficult to analytically solve the DAEM, the numerical techniques has been employed.

\section{Numerical Solution}

The integration in equations 11 and 12 goes from $E=0$ to $E=\infty$. The change of the lower limit of integration enables us to employ generally available mathematical techniques for the integration, without affecting the results, as outlined below $[18,40]$ :

$$
\alpha_{j}(t)=\int_{0}^{\infty} D_{j}(E) X_{j}(t, E) d E_{a} \cong \int_{-\infty}^{\infty} D_{j}(E) \alpha_{j}(t, E) d E
$$

Introducing a variable:

$$
\epsilon_{\mathrm{j}}=\frac{\left(E-\mathrm{E}_{0}\right)}{\sqrt{2 \sigma_{\mathrm{j}}}}
$$

Equation 14 can write as [40]:

$$
\begin{aligned}
& \alpha_{j}(t) \cong(2 \pi)^{-\frac{1}{2}} \sigma_{j}^{-1} \int_{-\infty}^{\infty} \exp \left[-\frac{\left(E-E_{0}\right)^{2}}{2 \sigma_{j}^{2}}\right] \alpha_{j}(t, E) d E= \\
& =\pi^{-\frac{1}{2}} \int_{-\infty}^{\infty} \exp \left(-\epsilon_{j}^{2}\right) \alpha_{j}\left(t, \epsilon_{\mathrm{j}}\right) d \epsilon_{j}
\end{aligned}
$$

where $\alpha_{j}\left(t, \epsilon_{j}\right)$ is $\alpha_{j}(t, E)$ expressed as a function

$$
\begin{aligned}
& \frac{d \alpha_{j}}{d t} \cong 1 / 2 \pi^{-\frac{1}{2}} . \\
& \cdot \sum_{i=1}^{N} w_{i} \exp \left(0,75 \mu_{i j}^{2}\right) d X_{j}\left(t, \mu_{i j}\right) \frac{1}{d t}
\end{aligned}
$$

The equation 4.35 can easily be evaluated by a Gauss - Hemite quadrature formula [40, 52, 53]:

$$
\alpha_{j}(t) \cong \pi^{-\frac{1}{2}} \sum_{i=1}^{N} w_{i} \alpha_{j}\left(t, \epsilon_{i j}\right)
$$

where $w_{i}$ is weight factors and $\epsilon_{i j}$ is the abscissas of the quadrature formula [18]. These quantities can be determined by well-known Fortran library functions [53].

Derivative of the equation (15):

$$
\begin{aligned}
& \frac{d \alpha_{j}}{d t} \cong \pi^{-\frac{1}{2}} \int_{-\infty}^{\infty} \exp \left(-\epsilon_{j}^{2}\right) d \alpha_{j}\left(t, \epsilon_{j}\right) d t d \epsilon_{j} \\
& \cong \pi^{-\frac{1}{2}} \sum_{i=1}^{N} w_{i} d \alpha_{j}\left(t, \epsilon_{i j}\right) \frac{1}{d t}
\end{aligned}
$$

Donskoi and McElwain [40, 54, 55], suggested that the energy domain of the integration should be rescaled by a factor of $0.5-0.3$ to increase the efficiency of the Gauss-Hemite quadrature formula. Here rescaling factor of $1 / 2$ is introduced by introducing a variable $\mu j[40]$ :

$$
\mu_{\mathrm{j}}=2 \epsilon_{\mathrm{j}}=\frac{2\left(E-\mathrm{E}_{0, \mathrm{j}}\right)}{\sqrt{2} \sigma_{\mathrm{j}}}
$$

Here $\alpha_{j}\left(t, \mu_{j}\right)$ is $\alpha(t, E)$ expressed as a function of $\mu_{j}$, and $w_{i}$ and $\mu_{i j}$ are the weight factors and abscissas of the Gauss-Hermite quadrature formula.

Considering above mentioned, equation (17) become:

$$
\begin{aligned}
& \frac{d \alpha_{j}}{d t} \cong 1 / 2 \pi^{-\frac{1}{2}} . \\
& \cdot \sum_{i=1}^{N} w_{i} \exp \left(0,75 \mu_{i j}^{2}\right) d X_{j}\left(t, \mu_{i j}\right) \frac{1}{d t}
\end{aligned}
$$

The performance of the present computers allows the application of high $N$ values. Várhegyi and Szabó [40] employed $\mathrm{N}=80$ in their calculations. In their calculations the relative precision of the Gauss-Hermite quadrature at $\mathrm{N}=80$ proved to be better then $10^{-7}$ in this way. The high precision can ensure that all features of the calculated curves will reflect the properties of the model employed, [40]. Várhegyi and Szabó, [40], calculated equation 4.96 without the rescaling and observed oscillations superposed on some of our simulated curves. It is known, however, that such oscillations appear when the numerical solution of the DAEM employs an insufficient precision [40].

The unknown model parameters can be estimated using the least squares method.

\section{CONCLUSION}

Well-chosen kinetic models fit the thermal decomposition data for complex biomass samples over a wide range of times and temperatures. The key to finding a model that will extrapolate well outside its calibration temperature range is to thoroughly decouple the effects of time, temperature, and extent of reaction [12].

The most versatile distributed reactivity models have a discrete energy distribution that is able to conform to the subtleties of the pyrolysis profile [12]. The conventional discrete distribution assumes the same frequency factor for all parallel reactions. However, the uniform frequency factor approximation is not always valid. Regarding, these methods are not as accurate for determining reactivity distribution parameters [12]. Consequently, a new method has been derived in which the discrete activation-energy distribution is derived by assuming a linear relationship between the logarithm of 
the frequency factor and the activation energy [12,26, $29,40]$. This model provides improved accuracy for the initial and final stages of the reaction for some samples when the kinetics are extrapolated far outside their range of calibration. This extension is most important for flash coal pyrolysis and natural gas generation.

The distributed activation energy model (DAEM) is the best way to represent mathematically the physical and chemical inhomogeneity of a substance.

\section{NOMENCLATURE}

Although most of the symbols are explained in the place where they appear, this section is a quick reference to the reader for the notation used along this work.

A

$\mathrm{A}_{\mathrm{i}}$

$\mathrm{A}_{\mathrm{j}}$

cj

$C_{\text {ter }, i}$

$D_{j}$

E

$E_{a}$

$E_{i}$

$E_{j}$

$k$

$k_{i}$

$\mathrm{m}$

$R$

$r_{i}$

$r_{\text {ter,i }}$

$\mathrm{t}$

$\mathrm{w}_{\mathrm{i}}$

$\mathrm{Xj}(\mathrm{E}, \mathrm{t}) \quad$ Solution of a 1st order kinetic equation at a given activation energy value E. $\left(\mathrm{X}_{\mathrm{j}}(0, \mathrm{E})=1\right.$, $\mathrm{Xj}(\infty, \mathrm{E})=0$.

$x$

$\mathrm{y} \quad$ product yield

$y_{i} \quad i$ th product of the pyrolysis reaction
$\mathrm{Y}_{j, i} \quad$ Yield coefficient $\mathrm{g} / \mathrm{g}$

\section{Greek symbols}

$\alpha_{j} \quad$ Fraction of the remaining component $j$

$\alpha_{i} \quad$ reacted biomass fraction

$\epsilon_{i j} \quad$ abscissas of the quadrature formula

$\mu_{i j} \quad$ abscissas of the Gauss-Hermite quadrature formula

\section{Subscripts and Superscripts}

$i \quad$ Pyrolysis products (volatile, charcoal, gases)

$i \quad$ Biomass pseudocomponent (hemicellulose, cellulose, lignin))

j Reaction component

$n \quad$ Reaction order

$\Sigma j$ - width-parameter (variation)

\section{REFERENCES}

[1] Pokol, G., G. Várhegyi, and D. Dollimore, Kinetic Aspects of Thermal Analysis. C R C Critical Reviews in Analytical Chemistry, 1988. 19(1): p. 65-93.

[2] Várhegyi, G., Aims and methods in non-isothermal reaction kinetics. Journal of Analytical and Applied Pyrolysis, 2007. 79(1-2): p. 278-288.

[3] Bridgwater, A., Thermal biomass conversion and utilization Biomass information system. 1996, Brussels, Luxembourg: Office for Official Publications of the European Communities.

[4] Prakash, N. and T. Karunanithi, Kinetic Modeling in Biomass Pyrolysis - A Review. Journal of Applied Sciences Research, 2008. 4(12): p. 16271636.

[5] Di Blasi, C., Comparison of semi-global mechanisms for primary pyrolysis of lignocellulosic fuels. Journal of Analytical and Applied Pyrolysis, 1998. 47(1): p. 43-64.

[6] Shafizadeh, F. and S. Chin Peter P, Thermal Deterioration of Wood, in Wood Technology: Chemical Aspects. 1977, American Chemical Society. p. 57-81.

$\mathrm{mg} / \mathrm{gm}^{3} \mathrm{~s}^{1}$ $\mathrm{mg} / \mathrm{gm}^{3} \mathrm{~s}^{1}$

7] Varhegyi, G., et al., Kinetics of the thermal decomposition of cellulose, hemicellulose, and sugarcane bagasse. Energy \& Fuels, 1989. 3(3): p. 329-335.

[8] Varhegyi, G., et al., Thermogravimetric-mass spectrometric characterization of the thermal decomposition of sunflower stem. Energy \& Fuels, 1989. 3(6): p. 755-760.

[9] Díaz, C.J.G., Understanding Biomass Pyrolysis Kinetics: Improved Modeling -based on comprehensive -thermokinetic Analysis, in Departament d'Enginyeria Química. 2006, Escola Tècnica Superior d'Enginyeria Industrial de Barcelona Universitat Politècnica de Catalunya: Barcelona, Spain. 
[10] Várhegyi, G., M.G.G. Grønli, and C. Di Blasi, Effects of Sample Origin, Extraction, and HotWater Washing on the Devolatilization Kinetics of Chestnut Wood. Industrial \& Engineering Chemistry Research, 2004. 43(10): p. 2356-2367.

[11] Manyà, J.J., E. Velo, and L. Puigjaner, Kinetics of Biomass Pyrolysis: a Reformulated ThreeParallel-Reactions Model. Industrial \& Engineering Chemistry Research, 2002. 42(3): p. 434-441.

[12] Burnham, A.K. and R.L. Braun, Global Kinetic Analysis of Complex Materials. Energy \& Fuels, 1998. 13(1): p. 1-22.

[13] Petar Gvero, Modeling devolatalisation process of biomass, 2002, PhD thesis, University of Belgrade Faculty of Mechanical Engineering

[14] Thurner, F. and U. Mann, Kinetic investigation of wood pyrolysis. Industrial \& Engineering Chemistry Process Design and Development, 1981. 20(3): p. 482-488.

[15]Koufopanos, C.A., A. Lucchesi, and G. Maschio, Kinetic modelling of the pyrolysis of biomass and biomass components. The Canadian Journal of Chemical Engineering, 1989. 67(1): p. 75-84.

[16] Orfão, J.J.M., F.J.A. Antunes, and J.L. Figueiredo, Pyrolysis kinetics of lignocellulosic materialsthree independent reactions model. Fuel, 1999. 78(3): p. 349-358.

[17] Mészáros, E., et al., Thermogravimetric and Reaction Kinetic Analysis of Biomass Samples from an Energy Plantation. Energy \& Fuels, 2004. 18(2): p. 497-507.

[18] Trninić, M., et al., Kinetics of Corncob Pyrolysis. Energy \& Fuels, 2012. 26(4): p. 2005-2013.

[19]Antal, M.J., Jr. and G. Varhegyi, Cellulose Pyrolysis Kinetics: The Current State of Knowledge. Industrial \& Engineering Chemistry Research, 1995. 34(3): p. 703-717.

[20] Milosavljevic, I. and E.M. Suuberg, Cellulose Thermal Decomposition Kinetics: Global Mass Loss Kinetics. Industrial \& Engineering Chemistry Research, 1995. 34(4): p. 1081-1091.

[21] Antal, M.J., G. Várhegyi, and E. Jakab, Cellulose Pyrolysis Kinetics: Revisited. Industrial \& Engineering Chemistry Research, 1998. 37(4): p. 1267-1275.

[22] Grønli, M., M.J. Antal, and G. Várhegyi, A RoundRobin Study of Cellulose Pyrolysis Kinetics by Thermogravimetry. Industrial \& Engineering Chemistry Research, 1999. 38(6): p. 2238-2244.

[23] Evans, R.J. and T.A. Milne, Molecular characterization of the pyrolysis of biomass. 1 . Fundamentals. Energy Fuels, 1987. 1: p. 311-9.

[24] Antal, M.J., Effects of reactor severity on the gasphase pyrolysis of cellulose- and kraft ligninderived volatile matter. Industrial \& Engineering Chemistry Product Research and Development, 1983. 22(2): p. 366-375.

[25] Antal, M., Jr., A Review of the Vapor Phase Pyrolysis of Biomass Derived Volatile Matter, in
Fundamentals of Thermochemical Biomass Conversion, R.P. Overend, T.A. Milne, and L.K. Mudge, Editors. 1985, Springer Netherlands. p. 511-537.

[26] Di Blasi, C., Modeling chemical and physical processes of wood and biomass pyrolysis. Progress in Energy and Combustion Science, 2008. 34(1): p. 47-90.

[27] Chan, W.-C.R., M. Kelbon, and B.B. Krieger, Modelling and experimental verification of physical and chemical processes during pyrolysis of a large biomass particle. Fuel, 1985. 64(11): p. 1505-1513.

[28]Gvero, P., Modeliranje procesa devolatalizacije biomase, Doktorska disertacija. 2002, Mašinski fakultet Univerziteta u Beogradu.

[29] Antal, M.J. and M. Grønli, The Art, Science, and Technology of Charcoal Production $\dagger$. Industrial \& Engineering Chemistry Research, 2003. 42(8): p. 1619-1640.

[30] Srivastava, V.K., Sushil, and R.K. Jalan, Prediction of concentration in the pyrolysis of biomass material-II. Energy Conversion and Management, 1996. 37(4): p. 473-483.

[31] Di Blasi, C., Heat, momentum and mass transport through a shrinking biomass particle exposed to thermal radiation. Chemical Engineering Science, 1996. 51(7): p. 1121-1132.

[32] Miller, R.S. and J. Bellan, A Generalized Biomass Pyrolysis Model Based on Superimposed Cellulose, Hemicelluloseand Liqnin Kinetics. Combustion Science and Technology, 1997. 126(1-6): p. 97137.

[33] Rath, J. and G. Staudinger, Cracking reactions of tar from pyrolysis of spruce wood. Fuel, 2001. 80(10): p. 1379-1389.

[34]Boroson, M.L., et al., Product yields and kinetics from the vapor phase cracking of wood pyrolysis tars. AIChE Journal, 1989. 35(1): p. 120-128.

[35] Morf, P.O., Secondary reactions of tar during thermochemical biomass conversion. 2001, Technische Wissenschaften ETH Zürich, Nr. 14341, 2001: Zürich.

[36] Morf, P., P. Hasler, and T. Nussbaumer, Mechanisms and kinetics of homogeneous secondary reactions of tar from continuous pyrolysis of wood chips. Fuel, 2002. 81(7): p. 843853.

[37] Karamarković, V., Sagorevanje i gasifikacija biomase, Naučna monografija.

[38] Acton, Q.A., Advances in Carbon Research and Application. 2013: ScholarlyEditions ${ }^{\mathrm{TM}}$, Atlanta, Georgia, USA.

[39] Avni, E., et al., Mathematical modelling of lignin pyrolysis. Fuel, 1985. 64(11): p. 1495-1501.

[40] Várhegyi, G., P. Szabó, and M.J. Antal, Kinetics of Charcoal Devolatilization. Energy \& Fuels, 2002. 16(3): p. 724-731.

[41] Vand, V., A theory of the irreversible electrical resistance changes of metallic films evaporated in 
vacuum. Proceedings of the Physical Society 1943. $55(3)$.

[42] Pitt, G.J., The Kinetics of the Evolution of Volatile Products from Coal. Fuel, 1962. 41: p. 264-274.

[43] Anthony, D.B., J.B. Howard, Coal Devolatilization and Hydrogasification. A.I.Ch.E. Journal of Analytical and Applied Physics, 1976: p. 625-655.

[44]Braun, R.L. and A.K. Burnham, Analysis of Chemical Reaction Kinetics Using a Distribution of Activation Energies and Simpler Models. Energy and Fuels, 1987. 1 p. 153-161.

[45] Saidi, M.S., M.R. Hajaligol, and F. Rasouli, Numerical simulation of a burning cigarette during puffing. Journal of Analytical and Applied Pyrolysis, 2004. 72(1): p. 141-152.

[46] Várhegyi, G., et al., Tobacco pyrolysis. Kinetic evaluation of thermogravimetric-mass spectrometric experiments. Journal of Analytical and Applied Pyrolysis, 2009. 86(2): p. 310-322.

[47] Várhegyi, G.b., et al., Thermogravimetric Study of Biomass Pyrolysis Kinetics. A Distributed Activation Energy Model with Prediction Tests. Energy \& Fuels, 2010. 25(1): p. 24-32.

[48] Trninic, M. Modeling and Optimisation of corn cob Pyrolysis. Doctoral thesis, University of Belgrade Faculty of Mechanical Engineering, 2015.

[49] Hornung, A., Transformation of Biomass. 2014: John Wiley \& Sons.

[50] Einhorn-Stoll, U., H. Kunzek, and G. Dongowski, Thermal analysis of chemically and mechanically modified pectins. Food Hydrocolloids, 2007. 21(7): p. 1101-1112.

[51] Gómez, C.J. and L. Puigjaner, Slow Pyrolysis of Woody Residues and an Herbaceous Biomass Crop: A Kinetic Study. Industrial \& Engineering Chemistry Research, 2005. 44(17): p. 6650-6660.

[52] Teukolsky, H.W.P.S.A. W.T. Vetterling, Numerical Recipes The Art of Scientific Computing, 3rd Edition. 2007.

[53] Numerics, V., Inc., and IMSL, Fortran 90 Mathematical Programming Library, Version 3.0; IMSL Software. Visual Numerics Inc.: Houston, TX, 1996.

[54] Donskoi, E. and D.L.S. McElwain, Optimization of coal pyrolysis modeling. Combustion and Flame, 2000. 122(3): p. 359-367.

[55] Várhegyi, G. Introduction to kinetic models for biomass pyrolysis. Part 1. in Nordic PhD course Analytical Techniques in Combustion. 2010. NTNU _ Triondheim, Norway.

[56] Shafizadeh, F., Alternative pathways for pyrolysis of cellulose, in ACS Energy and Fuels Symposia -
Symposium om mathematical modeling of biomass pyrolysis phenomena, Washington DC. 1983

[57] Varhegyi, G., E. Jakab, and M.J. Antal, Is the Broido-Shafizadeh Model for Cellulose Pyrolysis True? Energy \& Fuels, 1994. 8(6): p. 1345-1352.

[58] Broido, A., Kinetics of solid-phase cellulose pyrolysis, in Thermal Uses and Properties of Carbohydrates and Lignins, F. Shafizadeh, K.V. Sarkanen, D.A. Tillman, Editors. 1976, Academic Press. p. 19-36.

[59]Broido, A. and M.A. Nelson, Char yield on pyrolysis of cellulose. Combust Flame, 1975. 24: p. 263-268.Beskok, A., Karniadakis, G.E. and Trimmer, W.: Rarefaction and compressibility effects in gas microflows, Trans. ASME - J. Fluids Eng, Vol. 118, No. 3, pp. 448-456, 1996.

[60] Gross, A. W.: Gas film lubrication, John Wiley and Sons, New York, 1992.

[61] Stachowiak, G.W.: Numerical Characterization of wear particle morphology, in: Hutchings, I.M. (Ed.): New Directions in Tribology, Mechanical Engineering Publications Ltd., Bury St Edmunds, pp. 371-389, 1997.

[62] Stokes, J.: Production of Coated and Free-Standing Engineering Components using the HVOF (High Velocity Oxy-Fuel) Process, $\mathrm{PhD}$ thesis, School of Mechanical and Manufacturing Engineering, Dublin City University, Dublin, 2003.

[63] Lancaster, J.K.: Severe metallic wear, in: Proceedings of the Conference on Lubrication and Wear, 01-03.10.1957, London, pp. 1-7 or Paper 72.

\section{МАТЕМАТИЧКО МОДЕЛИРАЫЕ ПРИМАРНЕ И СЕКУНДАРНЕ ПИРОЛИЗЕ - ПРЕГЛЕД}

\section{М.P. Трнинић}

Процесом пиролизе је могуће биомасу конвертовати у течна, гасовита и чврста горива. Хемијска кинетика је од пресудног значаја за разумевање карактеристика процеса пиролизе и развој математичких модела којима се описује сам процес пиролизе. У литератури постоје многобројне, различите анализе којима се објашњавала кинетика процеса пиролизе. Међутим, услед хетерогености биомасе, сложености хемијских и физичких промена које се одвијају током процеса пиролизе биомасе, још увек је изазов развити једноставан, свеобухватан и прихватљив модел кинетике процеса који би универзално био применљив. У оквиру овог рада, урађен је преглед развоја кинетичких модела примарне и секундарне пиролизе биомасе. За сваки приказан модел, приступ моделовању механизма одвијања процеса је објашњен. 